\title{
Relation between systemic inflammatory markers, peripheral muscle mass, and strength in limb muscles in stable COPD patients
}

This article was published in the following Dove Press journal: International Journal of COPD

6 August 2015

Number of times this article has been viewed

\author{
Renata Ferrari' \\ Laura MO Caram' \\ Marcia M Faganello ${ }^{2}$ \\ Fernanda F Sanchez ${ }^{3}$ \\ Suzana E Tanni' \\ Irma Godoy' \\ 'Botucatu Medical School, \\ Department of Internal Medicine, \\ Pneumology Area, Botucatu, São Paulo, \\ ${ }^{2}$ Paulista State University, Department \\ of Physiotherapy and Occupational \\ Therapy, Marilia, São Paulo, \\ ${ }^{3}$ Federal University of Amazonas, \\ Department of Physiotherapy, Manaus, \\ Amazonas, Brazil
}

Correspondence: Renata Ferrari Faculdade de Medicina de Botucatu, Departamento Clínica Médica, Distrito de Rubião Júnior, s/n CEP 186|8-970, Botucatu/SP, Brazil

Tel +55 I4 3880 I I7 I

$\mathrm{Fax}+55 \quad 1438822238$

Email renataferrarifisio@gmail.com

\begin{abstract}
The aim of this study was to investigate the association between systemic inflammatory mediators and peripheral muscle mass and strength in COPD patients. Fifty-five patients (69\% male; age: $64 \pm 9$ years) with mild/very severe COPD (defined as forced expiratory volume in the first second $\left[\mathrm{FEV}_{1}\right]=54 \% \pm 23 \%$ ) were evaluated. We evaluated serum concentrations of IL-8, CRP, and TNF- $\alpha$. Peripheral muscle mass was evaluated by computerized tomography (CT); midthigh cross-sectional muscle area (MTCSA) and midarm cross-sectional muscle area (MACSA) were obtained. Quadriceps, triceps, and biceps strength were assessed through the determination of the one-repetition maximum. The multiple regression results, adjusted for age, sex, and $\mathrm{FEV}_{1} \%$, showed positive significant association between MTCSA and leg extension $(0.35$ [0.16, 0.55]; $P=0.001)$, between MACSA and triceps pulley $(0.45[0.31,0.58] ; P=0.001)$, and between MACSA and biceps curl $(0.34$ [0.22, 0.47$] ; P=0.001)$. Plasma TNF- $\alpha$ was negatively associated with leg extension $(-3.09[-5.99,-0.18] ; P=0.04)$ and triceps pulley $(-1.31[-2.35,-0.28] ; P=0.01)$, while plasma CRP presented negative association with biceps curl $(-0.06[-0.11,-0.01] ; P=0.02)$. Our results showed negative association between peripheral muscle mass (evaluated by CT) and muscle strength and that systemic inflammation has a negative influence in the strength of specific groups of muscles in individuals with stable COPD. This is the first study showing association between systemic inflammatory markers and strength in upper limb muscles.
\end{abstract}

Keywords: Inflammation, skeletal muscle, X-Ray Computed Tomography

\section{Introduction}

COPD is a preventable and treatable disease with some significant extrapulmonary effects that may contribute to the severity in individual patients. ${ }^{1}$ Skeletal muscle dysfunction is one of these systemic effects and contributes significantly to limited exercise capacity, reduced quality of life, and premature mortality. ${ }^{2}$ Furthermore, quadriceps weakness has been observed in one-third of COPD outpatients, and authors suggest that limb muscle dysfunction may occur even in individuals exhibiting mild to moderate airway obstruction. ${ }^{3}$

Muscle dysfunction appears to result from combined mass reduction and changes in distribution of fiber types and muscle metabolism. ${ }^{4}$ In addition, muscle disuse is an important risk factor for the development of atrophy in COPD patients. ${ }^{2}$ In point of fact, quadriceps wasting has been associated with physical inactivity in patients with early COPD. ${ }^{5}$ Although it has been well-established that limb muscles of COPD patients develop significant reductions in mass and cross-sectional areas, ${ }^{5,6}$ it is still unclear whether muscle weakness can be totally attributed to muscle mass depletion. In fact, van den Borst et al showed that lower lean body mass in smokers was not accompanied by lower maximal voluntary muscle force. ${ }^{7}$ 
Despite the fact that peripheral muscle dysfunction is probably multifactorial in origin, there is evidence suggesting a link with systemic inflammation. ${ }^{8,9}$ Quadriceps muscle strength was correlated negatively with plasma IL-8 levels in COPD patients during exacerbation, ${ }^{8}$ and plasma IL-6 and TNF- $\alpha$ levels were found to be increased and inversely associated with quadriceps muscle strength in stable COPD patients. ${ }^{9}$ Although most studies have been performed in lower limb muscles, ${ }^{6,10,11}$ a study reported that arm movement intensity is lower in patients with COPD compared with healthy control subjects. ${ }^{12}$ However, the association between systemic inflammatory markers and strength in specific groups of muscles in individuals with stable COPD is not clear. Our hypothesis is that given muscle weakness is not homogeneously distributed among muscle groups, the association between inflammatory markers and muscle strength may also be different. Therefore, the aim of this study was to investigate the association between systemic inflammatory mediators and upper and lower limb muscle mass and strength in COPD patients.

\section{Patients and methods}

Fifty-five consecutive COPD patients followed at the Outpatient Pulmonology Unit of Botucatu Medical School, São Paulo, Brazil participated in the study. Patients were included if they met the criteria for COPD according to the guidelines established in the Global Initiative for Chronic Obstructive Lung Disease and Brazilian Thoracic Society criteria: ${ }^{1,13}$ a postbronchodilator forced expiratory volume in the first second $\left(\mathrm{FEV}_{1}\right)$ /forced vital capacity $(\mathrm{FVC})$ ratio $<0.70$ and an increase in $\mathrm{FEV}_{1}$ of $<15 \%$ or $200 \mathrm{~mL}$ after inhalation of a $\beta 2$-agonist. Exclusion criteria included oral steroid use or exacerbations in the 3 months before enrollment in the study; diagnosis of other chronic diseases (ie, diabetes, renal failure, or cancer); or other respiratory disease (ie, asthma, bronchiectasis, bronchiolitis, or tuberculosis). Participants were made aware of the proposed study procedures and freely gave written informed consent. All procedures were approved by the Research Ethics Committee of Botucatu Medical School University Hospital.

\section{Pre- and postbronchodilator spirometry}

Spirometry was performed before and 15 minutes after the inhalation of $400 \mu \mathrm{g}$ salbutamol using the KOKO Spirometer (Ferraris Respiratory Inc, Louisville, CO, USA), according to criteria set by the American Thoracic Society. ${ }^{14} \mathrm{FEV}_{1}$ values were expressed in liters, percentages of $\mathrm{FVC}$, and percentages of reference values. ${ }^{15}$

\section{Dyspnea perception, exercise tolerance, and BODE index}

Dyspnea was assessed using a Brazilian version of the Medical Research Council dyspnea scale. ${ }^{16}$ The six-minute walk distance (6MWD) test was performed according to American Thoracic Society guidelines. ${ }^{17}$ The BODE index (measuring body mass index [BMI], airflow obstruction, dyspnea, and exercise capacity) was calculated using the model described by Celli et al. ${ }^{18}$ BODE scores were categorized as class $1(0-2)$, class $2(3-4)$, class $3(5-6)$, and class $4(7-10) .{ }^{18}$

\section{Nutritional assessment}

Body weight and height were measured by Filizola (mod-MIC2/B-A, São Paulo, SP, Brazil). BMI was calculated as:

$$
\text { BMI = weight in } \mathrm{kg} /(\text { height in } \mathrm{m})^{2} \text {. }
$$

Body composition was evaluated using bioelectrical impedance (BIA 101A; RJL Systems Inc, Clinton, MI, USA). Resistance was measured on the right side of the body in the supine position. Fat-free mass (FFM) $(\mathrm{kg})$ was calculated using a group-specific regression equation developed by Kyle et al. ${ }^{19}$ The FFM index (FFMI) was also calculated, as:

$$
\mathrm{FFMI}=\mathrm{FFM} /(\text { height } \text { in } \mathrm{m})^{2} \text {. }
$$

FFM depletion was defined as an FFMI $<15 \mathrm{~kg} / \mathrm{m}^{2}$ for women and $<16 \mathrm{~kg} / \mathrm{m}^{2}$ for men. ${ }^{20}$ Peripheral muscle mass was evaluated by computerized tomography (CT); midthigh cross-sectional muscle area (MTCSA) and midarm crosssectional muscle area (MACSA) were obtained, as previously described. ${ }^{11}$ Briefly, MTCSA was performed halfway between the pubic symphysis and the femur inferior condyle. In the arm, MACSA measurement was performed between the head of the humerus and the olecranon (SCT-7000 TS; Shimadzu, Kyoto, Japan). Each image was 10-20 mm thick and was taken at $120 \mathrm{kV}$, with a 1 -second scanning time.

\section{Blood sampling and analysis}

Fasting peripheral blood was collected early morning ( $8 \mathrm{am}$ to $10 \mathrm{am}$ ) and plasma stored at $-80^{\circ} \mathrm{C}$ until analysis. TNF- $\alpha$ and IL-8 were assessed in duplicate by high-sensitivity commercial kits, using enzyme linked immunosorbent assay (ELISA), according to manufacturer's instructions (BioSource International Inc, Camarillo, CA, USA). The lower detection limit was $0.5 \mathrm{pg} / \mathrm{mL}$ for TNF- $\alpha$ and $0.39 \mathrm{pg} / \mathrm{mL}$ 
for IL-8. CRP was assessed in duplicate by high-sensitivity particle-enhanced immunonephelometry (CardioPhase, Dade Behring Marburg GmbH, Marburg, USA), with a lower detection limit of $0.007 \mathrm{mg} / \mathrm{L}$.

\section{Peripheral muscle strength}

Peripheral muscle strength was assessed through the determination of the one-repetition maximum (1 RM). ${ }^{21}$ The agreed convention for $1 \mathrm{RM}$ is the heaviest weight that can be lifted throughout the complete range of motion related to the exercise performed; this was assessed for each of three exercises performed on weight training equipment. Patients were required to perform the following exercises: leg extension (quadriceps), triceps pulley (triceps), and biceps curl (biceps). A pretest warm-up of ten repetitions with light load was performed to minimize learning effects. The $1 \mathrm{RM}$ test was initiated at a weight near the suspected maximum to minimize repetition fatigue. All participants attained the 1 RM within four attempts. A total of 2-3 minutes of rest was allowed between repetitions. The Valsalva maneuver was avoided, and the correct exercise performance technique for each muscle group was emphasized.

\section{Statistical analysis}

All variables were summarized using means and standard deviations or median interquartile range $(25 \%-75 \%)$. Either the Student's $t$-test or Mann-Whitney was performed to compare characteristics between COPD I/II and COPD III/IV. The chi-squared test was used to evaluate the qualitative variables. We analyzed the association of systemic inflammation (TNF- $\alpha$, CRP, and IL8) and cross-sectional muscle area (MACSA and MTCSA) with peripheral muscle strength (leg extension, triceps pulley, and biceps curl), using multiple linear regression with robust standard errors with adjustment for potential confounders (age, sex, and $\mathrm{FEV}_{1}$ ). A $P<0.05$ was considered for statistical significance (STATA 10.0; STATA Corp, College Station, TX, USA).

\section{Results}

Characteristics of the COPD patients in total group and according to GOLD classification are shown in the Table 1. There was no difference in peripheral muscle mass, strength, and systemic inflammation between patients with COPD I/II and COPD III/ IV. There was no difference in the proportion of patients with FFM depletion $(P=0.62)$ between patients with COPD I/II and II/IV . According to BODE index, ${ }^{18} 58 \%$ were in class $1,25 \%$ in class $2,13 \%$ were in class 3 , and $4 \%$ were in class 4 .

The multiple regression results, adjusted for age, sex, and $\mathrm{FEV}_{1} \%$ showed positive significant association between upper and lower local muscle mass, strength, and systemic inflammation. MTCSA was associated to 1 RM leg extension, and MACSA to 1 RM triceps pulley and biceps curl.

Table I Characteristics of the COPD patients in total group and according to GOLD classification

\begin{tabular}{|c|c|c|c|c|}
\hline Variables & $\begin{array}{l}\text { Total group } \\
(n=55)\end{array}$ & $\begin{array}{l}\text { COPD I/II } \\
(n=29)\end{array}$ & $\begin{array}{l}\text { COPD III/IV } \\
(n=26)\end{array}$ & $P$-value \\
\hline Age, years & $64.0 \pm 9.2$ & $63.3 \pm 10.0$ & $66.0 \pm 8.3$ & 0.29 \\
\hline Sex (F/M), n & $17 / 38$ & $11 / 18$ & $6 / 20$ & 0.36 \\
\hline $\mathrm{FEV}_{1}(\%)^{*}$ & $51.0(39.2-66.2)$ & $64.0(55.7-78.5)$ & $38.5(29.0-42.0)$ & $<0.001$ \\
\hline Active smoking, $\mathrm{n}$ & 15 & 8 & 7 & 0.80 \\
\hline 6MWD (m) & $440.3 \pm 85.8$ & $447.2 \pm 96.6$ & $432.7 \pm 73.0$ & 0.53 \\
\hline MRC score & $1.0(1.0-2.0)$ & $1.0(1.0-1.2)$ & $1.0(1.0-2.0)$ & 0.08 \\
\hline BMI $\left(\mathrm{kg} / \mathrm{m}^{2}\right)$ & $25.4 \pm 5.1$ & $26.4 \pm 5.6$ & $24.2 \pm 4.2$ & 0.10 \\
\hline $\mathrm{FFM}(\mathrm{kg})$ & $41.4 \pm 7.2$ & $41.8 \pm 6.8$ & $41.0 \pm 7.6$ & 0.71 \\
\hline FFM index $\left(\mathrm{kg} / \mathrm{m}^{2}\right)$ & $16.0(\mid 4.8-17.6)$ & $16.9(\mid 4.8-17.6)$ & $15.8(15.0-17.6)$ & 0.53 \\
\hline $\operatorname{MACSA}\left(\mathrm{cm}^{2}\right)$ & $35.7 \pm 9.3$ & $36.7 \pm 9.0$ & $34.6 \pm 9.8$ & 0.41 \\
\hline MTCSA $\left(\mathrm{cm}^{2}\right)$ & $122.7 \pm 26.9$ & $126.2 \pm 28.4$ & $|I 8.8 \pm 25|$. & 0.31 \\
\hline Leg extension (kg) & $80.0(65.0-100.0)$ & $90.0(70.0-104.5)$ & $77.5(60.0-95.0)$ & 0.09 \\
\hline Biceps curl (kg) & $20.0(16.0-24.0)$ & $20.0(18.0-24.0)$ & $20.0(14.0-23.0)$ & 0.60 \\
\hline Triceps pulley (kg) & $18.4 \pm 5.6$ & $19.1 \pm 5.5$ & $17.5 \pm 5.7$ & 0.29 \\
\hline TNF- $\alpha(p g / m L)$ & $4.3(4.0-4.7)$ & $4.5(4.2-4.8)$ & $4.1(3.8-4.4)$ & 0.05 \\
\hline IL-8 (pg/mL) & $5.3(3.7-15.5)$ & $5.1(3.4-21.2)$ & $5.3(3.9-10.6)$ & 0.74 \\
\hline CRP (mg/L) & $5.9(2.7-9.3)$ & $4.4(2.6-7.9)$ & $6.8(2.8-9.7)$ & 0.45 \\
\hline
\end{tabular}

Notes: Values are presented as mean \pm SD or median (interquartile range). $P<0.05$ (Student's $t$-test or Mann-Whitney and chi-square). COPD I/II indicates mild/moderate disease, according to GOLD classification; COPD III/IV indicates severe/very severe. *Expressed as percentage of predicted.

Abbreviations: 6MWD, six-minute walking distance test; BMI, body mass index; F, Female; FEV , forced expiratory volume in the first second; FFM, fat-free mass; GOLD, Global Initiative for Chronic Obstructive Lung Disease; M, Male; MACSA, midarm cross-sectional muscle area; MRC, Modified Medical Research Council dyspnea scale; MTCSA, midthigh cross-sectional muscle area; SD, standard deviation. 
Table 2 Linear regression models, with robust standard errors, for I RM leg extension, I RM triceps pulley, and I RM biceps curl

\begin{tabular}{|c|c|c|c|}
\hline Model & Variables & $\begin{array}{l}\text { Coefficient } \\
(95 \% \mathrm{Cl})\end{array}$ & $P$-value \\
\hline \multirow[t]{5}{*}{ I RM leg extension } & Age, years & $0.19(-0.13,0.52)$ & 0.23 \\
\hline & Sex, Male & $5.20(-4.23,14.66)$ & 0.27 \\
\hline & $\mathrm{FEV}_{1}(\%)^{*}$ & $-0.11(-0.23,0.01)$ & 0.07 \\
\hline & $\operatorname{MTCSA}\left(\mathrm{cm}^{2}\right)$ & $0.35(0.16,0.55)$ & $0.00 I^{* *}$ \\
\hline & TNF- $\alpha(p g / m L)$ & $-3.09(-5.99,-0.18)$ & $0.04 * *$ \\
\hline \multirow[t]{5}{*}{ I RM triceps pulley } & Age, years & $-0.42(-0.21,0.13)$ & 0.62 \\
\hline & Sex, Male & $-0.73(-4.18,2.7 I)$ & 0.67 \\
\hline & $\mathrm{FEV}_{1}(\%)^{*}$ & $0.19(-0.02,0.06)$ & 0.38 \\
\hline & $\operatorname{MACSA}\left(\mathrm{cm}^{2}\right)$ & $0.45(0.3 \mathrm{I}, 0.58)$ & $0.00 I^{* *}$ \\
\hline & TNF- $\alpha(p g / m L)$ & $-1.31(-2.35,-0.28)$ & $0.01 * *$ \\
\hline \multirow[t]{5}{*}{ I RM biceps curl } & Age (years) & $0.03(-0.14,0.21)$ & 0.68 \\
\hline & Male sex & $-2.46(-6.01,1.07)$ & 0.17 \\
\hline & $\mathrm{FEV}_{1}(\%)^{*}$ & $0.02(-0.02,0.07)$ & 0.28 \\
\hline & $\operatorname{MACSA}\left(\mathrm{cm}^{2}\right)$ & $0.34(0.22,0.47)$ & $0.00 I^{* *}$ \\
\hline & CRP (mg/L) & $-0.06(-0.11,-0.01)$ & $0.02 * *$ \\
\hline
\end{tabular}

Notes: $P<0.05$ (multiple linear regression with robust standard errors). *Expressed as percentage of predicted. **Significant.

Abbreviations: I RM, one-repetition maximum; $\mathrm{Cl}$, confidence interval; $\mathrm{FEV}_{1}$, forced expiratory volume in the first second (\% of predicted); MACSA, midarm cross-sectional muscle area; MTCSA, midthigh cross-sectional muscle area.

Plasma TNF- $\alpha$ was negatively associated with 1 RM leg extension and triceps pulley, while plasma CRP presented negative association with 1 RM biceps curl (Table 2). IL-8 did not show association with muscles strength or muscle mass (data not shown).

We did not find association of muscle mass (as evaluated by CT scan or by bioelectrical impedance) and systemic inflammation.

\section{Discussion}

The results of this study showed that increased TNF- $\alpha$ levels were associated with reduced strength of quadriceps and triceps, while higher CRP levels were associated with reduced strength of biceps. Previous study has showed an inverse relationship between systemic inflammatory markers and quadriceps strength in stable COPD $;{ }^{9}$ however, this is the first study showing association between systemic inflammatory markers and strength in upper limb muscles. Peripheral muscle mass, evaluated by $\mathrm{CT}$, and not systemic muscle mass, was also associated with reduced muscle strength in COPD patients; however, no influence of inflammation on peripheral or systemic muscle mass was shown.

There is evidence that inflammation in COPD patients is characterized by an increase in level of CRP, IL-6, IL-8, and TNF- $\alpha$ in peripheral blood. ${ }^{22,23}$ The presence of local inflammation in the skeletal muscle of patients with COPD is still a controversial issue. ${ }^{2}$ While one study showed increased levels of TNF- $\alpha$ expression in the peripheral muscle of COPD patients, ${ }^{24}$ other investigators could not reproduce these findings. ${ }^{25,26}$ The notion that systemic inflammation contributes to skeletal muscle dysfunction in COPD patients is supported by the fact that many proinflammatory cytokines can adversely influence skeletal muscle through activation of muscle proteolysis and inhibition of protein synthesis. ${ }^{27}$ The exact origin of these circulating cytokines is unclear but might include the overspill of systemic inflammation into muscle, activated leukocytes, and organ systems, such as bone marrow and skeletal muscle itself. ${ }^{28}$ Experimental studies have shown that inflammatory markers, such as increased blood levels of TNF- $\alpha,{ }^{29}$ promote muscle wasting by enhancing the activity of the ubiquitin proteasome pathway ${ }^{30}$ or by inducing apoptosis. ${ }^{31}$ Furthermore, TNF- $\alpha$ may cause weakness without muscle wasting by directly compromising contractile function. ${ }^{32}$ In agreement with these previous, findings our study showed that increased systemic levels of TNF- $\alpha$ were associated with quadriceps strength but not with muscle mass. Similarly, Yende et $\mathrm{al}^{9}$ found an inverse association of TNF- $\alpha$ and IL-6 levels with quadriceps strength. Although participants with obstruction had higher CRP levels, CRP was not an independent predictor of quadriceps strength in the same study. ${ }^{9}$ Altogether, these results reinforce the inverse relationship between systemic inflammatory markers and quadriceps muscle strength in stable COPD patients.

We verified an inverse association between inflammatory markers and upper limb strength. This finding is in contrast with those of Yende et $\mathrm{al}^{9}$ where no association between inflammatory markers and handgrip or respiratory muscle strength was shown. Yende et al suggest that upper extremity muscle strength is preserved in patients with COPD, which may explain the weak association between inflammatory markers and handgrip strength. In fact, distal strength (handgrip) could be possibly preserved since patients are able to continue to perform activities of daily living that involve repeated handgrip movements, including gripping, holding, and carrying objects. In contrast, reduced proximal upper limb muscle strength, as assessed in the present study by shoulder abduction, can be explained by a reduction in unsupported arm activities in order to avoid dyspnea. ${ }^{33}$ Furthermore, Meijer et al ${ }^{12}$ showed that patients with COPD spent more time in arm postures compared with arm activities, and that arm movement intensity was lower compared with healthy control subjects.

Interestingly, we also found that peripheral muscle mass evaluated by CT was associated with reduced muscle strength. 
Similarly, Seymour et al showed that ultrasound measurement of rectus femoral muscle cross-sectional area was related to strength. ${ }^{34}$ Although repeated reports have described that when limb muscle strength is normalized per cross-sectional area or mass, no differences can be observed between COPD patients and control subjects. ${ }^{11,35}$ Malaguti et $\mathrm{al}^{36}$ showed that COPD patients had a reduction of isokinetic strength and total work of knee extension and FFM when compared with controls. The coefficients of allometric correction of the isometric contraction and total work were significantly higher in patients compared with controls. The authors concluded that the decrease in FFM did not explain all the changes in peripheral muscle function in COPD patients without depletion. Moreover, reduced muscle mass relates to an impairment in muscle strength, but it does not account for abnormal muscle endurance, ${ }^{35}$ which seems to be related to alterations in skeletal muscle bioenergetics. ${ }^{37}$

When we compared mild/moderate and severe/very severe patients, we found no difference between these groups, although quadriceps strength had a tendency to be lower in severe and very severe patients. One possible explanation is that in our study, we found no significant difference in prevalence of FFM depletion between the different stages of COPD. In addition, body composition was very similar between the groups in our study. However, a large sample size could allow the identification of differences in muscle strength and body compositions between disease severities.

The present study has some limitations. We evaluated muscle strength using 1 RM. Previous study showed that isometric strength was the most sensitive method to detect differences among subsets of subjects. ${ }^{35}$ On the other hand, as indicated by Vilaro et $\mathrm{al}^{35} 1 \mathrm{RM}$ strength can be considered for routine clinical use since it was highly correlated with isometric and isokinetic forces. Evaluation of physical activity and arm activities during daily life could add information to the study since physical activity was related to lower risk of high levels of circulating TNF- $\alpha$ and CRP $\geq 3 \mathrm{mg} / \mathrm{L} .{ }^{38} \mathrm{We}$ accept that further longitudinal studies investigating skeletal muscle strength and systemic inflammation should include detailed analysis of physical activity. In addition, we did not evaluate the influence of the interaction between inflammatory markers and muscle depletion on muscle strength; therefore we cannot make assumptions about the combined influence of inflammation and muscle depletion on muscle function.

\section{Conclusion}

In summary, our findings confirm the association between systemic inflammatory markers and strength in specific groups of muscles in individuals with stable COPD. While TNF- $\alpha$ was inversely associated with quadriceps and triceps strength, CRP was inversely associated with biceps strength. Furthermore, peripheral muscle mass, evaluated by CT, was also associated with reduced muscle strength. Finally, no differences in these inflammatory mediators were found between patients with and without FFM depletion.

\section{Disclosure}

The authors report no conflicts of interest in this work.

\section{References}

1. Global Initiative for Chronic Obstructive Lung Disease. Global Strategy for the Diagnosis, Management, and Prevention of Chronic Obstructive Lung Disease - Updated 2014. Vancouver, WA: Global Initiative for Chronic Obstructive Lung Disease; 2014. Available from: http:// www.goldcopd.org/uploads/users/files/GOLD_Report2014_Feb07.pdf. Accessed January 26, 2015.

2. Maltais F, Decramer M, Casaburi R, et al; ATS/ERS Ad Hoc Committee on Limb Muscle Dysfunction in COPD. An official American Thoracic Society/European Respiratory Society statement: update on limb muscle dysfunction in chronic obstructive pulmonary disease. $\mathrm{Am}$ J Respir Crit Care Med. 2014;189(9):e15-e62.

3. Seymour JM, Spruit MA, Hopkinson NS, et al. The prevalence of quadriceps weakness in COPD and the relationship with disease severity. Eur Respir J. 2010;36(1):81-88.

4. Mathur S, Brooks D, Carvalho CR. Structural alterations of skeletal muscle in copd. Front Physiol. 2014;5:104.

5. Shrikrishna D, Patel M, Tanner RJ, et al. Quadriceps wasting and physical inactivity in patients with COPD. Eur Respir J. 2012;40(5): $1115-1122$.

6. Hopkinson NS, Tennant RC, Dayer MJ, et al. A prospective study of decline in fat free mass and skeletal muscle strength in chronic obstructive pulmonary disease. Respir Res. 2007;8:25.

7. van den Borst B, Koster A, Yu B, et al. Is age-related decline in lean mass and physical function accelerated by obstructive lung disease or smoking? Thorax. 2011;66(11):961-969.

8. Spruit MA, Gosselink R, Troosters T, et al. Muscle force during an acute exacerbation in hospitalised patients with COPD and its relationship with CXCL8 and IGF-I. Thorax. 2003;58(9):752-756.

9. Yende S, Waterer GW, Tolley EA, et al. Inflammatory markers are associated with ventilatory limitation and muscle dysfunction in obstructive lung disease in well functioning elderly subjects. Thorax. 2006;61(1): $10-16$.

10. Hamilton AL, Killian KJ, Summers E, Jones NL. Muscle strength, symptom intensity, and exercise capacity in patients with cardiorespiratory disorders. Am J Respir Crit Care Med. 1995;152(6 Pt 1): 2021-2031.

11. Bernard S, LeBlanc P, Whittom F, et al. Peripheral muscle weakness in patients with chronic obstructive pulmonary disease. Am J Respir Crit Care Med. 1998;158(2):629-634.

12. Meijer K, Annegarn J, Lima Passos V, et al. Characteristics of daily arm activities in patients with COPD. Eur Respir J. 2014;43(6): $1631-1641$.

13. Jardim JR, Oliveira JA, Nascimento O. II Consenso Brasileiro de DPOC. J Bras Pneumol. 2004;30(Supp1 5):S1-S42. Portuguese.

14. American Thoracic Society. Standardization of spirometry - 1987 update. Statement of the American Thoracic Society. Am Rev Respir Dis. 1987;136(5):1285-1298.

15. Knudson RJ, Lebowitz MD, Holberg CJ, Burrows B. Changes in the normal maximal expiratory flow-volume curve with growth and aging. Am Rev Respir Dis. 1983;127(6):725-734. 
16. Kovelis D, Segretti NO, Probst VS, Lareau SC, Brunetto AF, Pitta F. Validation of the Modified Pulmonary Functional Status and Dyspnea Questionnaire and the Medical Research Council scale for use in Brazilian patients with chronic obstructive pulmonary disease. J Bras Pneumol. 2008;34(12):1008-1018.

17. ATS Committee on Proficiency Standards for Clinical Pulmonary Function Laboratories. ATS statement: guidelines for the six-minute walk test. Am J Respir Crit Care Med. 2002;166(1):111-117.

18. Celli BR, Cote CG, Marin JM, et al. The body-mass index, airflow obstruction, dyspnea, and exercise capacity index in chronic obstructive pulmonary disease. N Engl J Med. 2004;350(10):1005-1012.

19. Kyle UG, Pichard C, Rochat T, Slosman DO, Fitting JW, Thiebaud D. New bioelectrical impedance formula for patients with respiratory insufficiency: comparison to dual-energy X-ray absorptiometry. Eur Respir J. 1998;12(4):960-966.

20. Schols A, Broekhuizen R, Weling-Scheepers CA, Wouters EF. Body composition and mortality in chronic obstructive pulmonary disease. Am J Clin Nutr. 2005;82(1):53-59.

21. Powers SK, ET H. Testes de esforço para a avaliação do desempenho. In: Powers SK, Howley ET, editors. Fisiologia do Exercício: Teoria e Aplicação ao Condicionamento e ao Desempenho. São Paulo: Manole. 2000:371-390. Portuguese.

22. Tanni SE, Pelegrino NR, Angeleli AY, Correa C, Godoy I. Smoking status and tumor necrosis factor-alpha mediated systemic inflammation in COPD patients. J Inflamm (Lond). 2010;7:29.

23. Agustí A, Edwards LD, Rennard SI, et al; Evaluation of COPD Longitudinally to Identify Predictive Surrogate Endpoints (ECLIPSE) Investigators. Persistent systemic inflammation is associated with poor clinical outcomes in COPD: a novel phenotype. PLoS One. 2012;7(5): e37483.

24. Montes de Oca M, Torres SH, De Sanctis J, Mata A, Hernández N, Tálamo C. Skeletal muscle inflammation and nitric oxide in patients with COPD. Eur Respir J. 2005;26:390-397.

25. Barreiro E, Schols AM, Polkey MI, et al; ENIGMA in COPD project. Cytokine profile in quadriceps muscles of patients with severe COPD. Thorax. 2008;63(2):100-107.

26. Barker BL, McKenna S, Mistry V, et al. Systemic and pulmonary inflammation is independent of skeletal muscle changes in patients with chronic obstructive pulmonary disease. Int J Chron Obstruct Pulmon Dis. 2014;9:975-981.
27. Degens H, Gayan-Ramirez G, van Hees HW. Smoking-induced skeletal muscle dysfunction: from evidence to mechanisms. Am J Respir Crit Care Med. 2015;191(6):620-625.

28. Barnes PJ, Celli BR. Systemic manifestations and comorbidities of COPD. Eur Respir J. 2009;33(5):1165-1185.

29. Tang K, Wagner PD, Breen EC. TNF-alpha-mediated reduction in PGC-1alpha may impair skeletal muscle function after cigarette smoke exposure. J Cell Physiol. 2010;222(2):320-327.

30. Langen RC, Schols AM, Kelders MC, van der Velden JL, Wouters EF, Janssen-Heininger YM. Muscle wasting and impaired muscle regeneration in a murine model of chronic pulmonary inflammation. Am J Respir Cell Mol Biol. 2006;35(6):689-696.

31. Carbó N, Busquets S, van Royen M, Alvarez B, López-Soriano FJ, Argilés JM. TNF-alpha is involved in activating DNA fragmentation in skeletal muscle. Br J Cancer. 2002;86(6):1012-1016.

32. Reid MB, Lännergren J, Westerblad H. Respiratory and limb muscle weakness induced by tumor necrosis factor-alpha: involvement of muscle myofilaments. Am J Respir Crit Care Med. 2002;166(4):479-484.

33. Miranda EF, Malaguti C, Corso SD. Peripheral muscle dysfunction in COPD: lower limbs versus upper limbs. J Bras Pneumol. 2011;37(3): 380-388.

34. Seymour JM, Ward K, Sidhu PS, et al. Ultrasound measurement of rectus femoris cross-sectional area and the relationship with quadriceps strength in COPD. Thorax. 2009;64(5):418-423.

35. Vilaro J, Rabinovich R, Gonzalez-deSuso JM, et al. Clinical assessment of peripheral muscle function in patients with chronic obstructive pulmonary disease. Am J Phys Med Rehabil. 2009;88(1):39-46.

36. Malaguti C, Nery LE, Dal Corso S, et al. Scaling skeletal muscle function to mass in patients with moderate-to-severe COPD. Eur J Appl Physiol. 2006;98(5):482-488.

37. Rabinovich RA, Vilaró J. Structural and functional changes of peripheral muscles in chronic obstructive pulmonary disease patients. Curr Opin Pulm Med. 2010;16(2):123-133.

38. Garcia-Aymerich J, Serra I, Gómez FP, et al; Phenotype and Course of COPD Study Group. Physical activity and clinical and functional status in COPD. Chest. 2009;136(1):62-70.
International Journal of COPD

\section{Publish your work in this journal}

The International Journal of COPD is an international, peer-reviewed journal of therapeutics and pharmacology focusing on concise rapid reporting of clinical studies and reviews in COPD. Special focus is given to the pathophysiological processes underlying the disease, intervention programs, patient focused education, and self management protocols.

\section{Dovepress}

This journal is indexed on PubMed Central, MedLine and CAS. The manuscript management system is completely online and includes a very quick and fair peer-review system, which is all easy to use. Visit http://www.dovepress.com/testimonials.php to read real quotes from published authors. 